\title{
Thermal Conductivity of Gypsum at High Temperatures A Combined Experimental and Numerical Approach
}

\begin{abstract}
I. Rahmanian, Y. Wang
Performance of gypsum board based systems in fire is highly influenced by the temperature-dependant thermal conductivity of gypsum boards, yet there is a wide difference in the thermal conductivity values used in literature. Presented here is a hybrid method to determine the effective thermal conductivity of gypsum boards at high temperatures, based on using small-scale experimental results and a thermal conductivity model which includes the effects of radiation in voids.
\end{abstract}

Keywords: gypsum board, thermal conductivity, high temperatures, radiation in voids, porous material, passive fire protection, fire resistance

\section{Introduction}

Gypsum board based systems are now widely used in buildings, as walls or ceilings, to provide passive fire protection. The basis of the fire resistance of such systems lies in low thermal conductivity and the evaporation of the water content of the gypsum board, which absorbs a considerable amount of heat, thereby delaying temperature rise through the system. To accurately model the performance of such systems in fire condition, their thermal properties should be known.

Thermal properties of gypsum are temperature-dependent and among them, thermal conductivity has a critical influence, but there is a wide difference in reported values in literature. Given the effects of porosity, non-homogeneity and moisture in gypsum, direct experimental measurement of thermal conductivity of gypsum at high temperatures is not an easy task. As an alternative, this paper proposes a hybrid numerical and experimental method to extract the thermal conductivity of gypsum. A one-dimensional finite difference heat conduction programme has been developed to predict the temperature development through the thickness of the gypsum board, based on an initial estimate of the thermal conductivity-temperature relationship as a function of porosity and radiation within the voids. This relationship is then calibrated by comparing numerical results with the experimental results from small-scale fire tests, so that the temperature history of the specimen calculated by the programme closely matches the temperatures recorded during the test. This method has been found to yield more consistent results than those reported in literature.

\section{Outline of the numerical analysis method}

The transient heat transfer through a gypsum board is modelled using one-dimensional Finite Difference formulation. A computer program has been developed and implemented in the familiar environment of Microsoft Excel using VBA. The modelling procedure has been thoroughly validated [1] by comparisons with a number of analytical solutions and simulation results, using ABAQUS/Standard. The following describes the basis of the modelling method.

\subsection{One-dimensional finite difference formulation}

Fourier's law of conduction in one dimension with no heat generation is expressed as:

$$
\frac{\partial}{\partial x}\left(k(T) \frac{\partial T(x, t)}{\partial x}\right)=\rho c \frac{\partial T(x, t)}{\partial t},
$$

where $T(x, t)$ is temperature $\left({ }^{\circ} \mathrm{C}\right)$,

$$
\begin{array}{ll}
k(T) & \text { is thermal conductivity }\left(\mathrm{W} / \mathrm{m} \cdot{ }^{\circ} \mathrm{C}\right), \\
\rho & \text { is material density }\left(\mathrm{kg} / \mathrm{m}^{3}\right), \\
c & \text { is specific heat of material }\left(\mathrm{J} / \mathrm{kg} \cdot{ }^{\circ} \mathrm{C}\right), \\
t & \text { is time }(\mathrm{sec}), \\
x & \text { is the coordinate }(0 \leq x \leq L, L \text { being the thick- } \\
& \text { ness of the panel). }
\end{array}
$$

Choosing the explicit technique, the temperature of a volume cell (refer to Figs. 1 and 2) at a time step is computed directly based on the temperatures of the adjacent cells in the last time step, which leads to a very simple scheme of computation [2]:

(i) For a typical node $m$ within the material (Fig. 1):

$T_{m}^{\prime}=F_{0}\left[\frac{2\left(k_{m-1, m} T_{m-1}+k_{m+1, m} T_{m+1}\right)}{k_{m-1, m}+k_{m+1, m}}+T_{m}\left(\frac{1}{F_{0}}-2\right)\right]$,

where $F_{0}$ is defined as:

$$
F_{0}=\frac{\left(k_{m-1, m}+k_{m+1, m}\right) \Delta t}{2 \rho c(\Delta x)^{2}}
$$

$T_{m}^{\prime}$ is the temperature of $m$ in the subsequent time step and $k_{i, j}$ is the thermal conductivity at the average temperature of cells $i$ and $j$ :

$$
k_{i, j}=k\left(\frac{T_{i}+T_{j}}{2}\right)
$$


Numerical stability under the explicit scheme requires:

$$
\Delta t \leq \frac{\rho c(\Delta x)^{2}}{\left(k_{m-1, m}+k_{m+1, m}\right)} .
$$

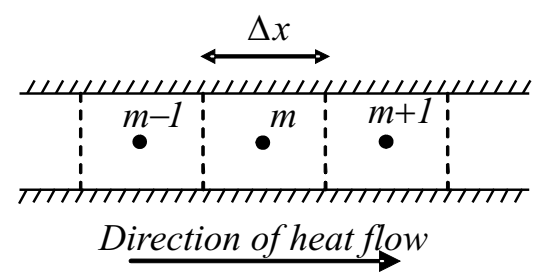

Fig. 1: Finite difference discretization for node $m$ within the material

(ii) For a boundary node, when subjected to convective and radiative boundary conditions (Fig. 2):

$$
\begin{aligned}
T_{1}^{\prime} & =2 F_{0}\left[T_{2}+\frac{h \Delta x}{k_{1}} T_{\infty}+\left(\frac{1}{2 F_{0}}-1-\frac{h \Delta x}{k_{1}}\right) T_{1}\right] \\
& +\phi E \sigma\left[\left(T_{\infty}+273\right)^{4}-\left(T_{1}+273\right)^{4}\right] \frac{2 \Delta t}{\rho c \Delta x},
\end{aligned}
$$

where $F_{0} \quad$ is $F_{0}=\frac{k_{1} \Delta t}{\rho c(\Delta x)^{2}}$,

$h(T) \quad$ is convection heat transfer coefficient $\left(\mathrm{W} / \mathrm{m}^{2} \cdot{ }^{\circ} \mathrm{C}\right)$,

$T_{\infty} \quad$ is the ambient temperature $\left({ }^{\circ} \mathrm{C}\right)$,

$\phi \quad$ is a geometric "view factor",

$E \quad$ is the effective emissivity,

$\sigma \quad$ is Stefan-Boltzmann constant

$$
\left(5.67 \times 10^{-8} \mathrm{~W} / \mathrm{m}^{2} \cdot \mathrm{K}^{4}\right) \text {. }
$$

Numerical stability limits the time step to:

$$
\Delta t \leq \frac{0.5 \rho c(\Delta x)^{2}}{k_{1}}\left[1+\frac{h \Delta x}{k_{1}}+\frac{\phi E \sigma \Delta x}{k_{1}} \cdot \frac{\left(T_{1}+273\right)^{4}}{T_{1}}\right]^{-1} .
$$

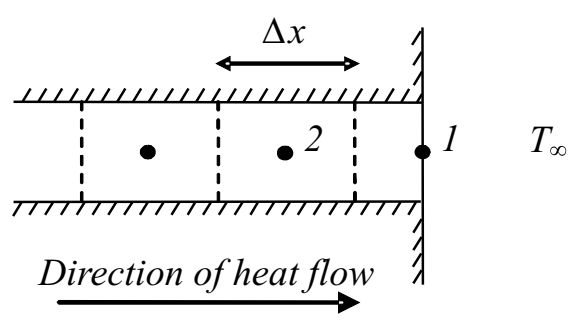

Fig. 2: Finite difference discretization for a boundary node

\subsection{Initial and boundary conditions}

Gypsum board is assumed to have a uniform initial temperature equal to the ambient temperature.

On the unexposed boundary, the convective heat transfer coefficient $(h)$ is assumed to be constant and the value is taken as $10 \mathrm{~W} / \mathrm{m}^{2} \cdot{ }^{\circ} \mathrm{C}$. The surface of gypsum plasterboards is laminated by paper with emissivity of $0.8-0.9$, as reported in reference [3]. Thus, the surface emissivity of the board is taken as 0.8 and the view factor equals unity. For extraction of thermal conductivity based on fire test results, the recorded temperatures on the exposed surface are used as input data.

\subsection{Specific heat and density}

The temperature-dependent specific heat of gypsum experiences two peaks corresponding to the two dehydration reactions of gypsum, as shown in Fig. 3. These peaks represent the energy consumed to dissociate and evaporate water and include the effect of water movement and recondensation of water in cooler regions of gypsum [4]. The base value of the specific heat is $950 \mathrm{~J} / \mathrm{kg} \cdot{ }^{\circ} \mathrm{C}$, as reported by Mehaffey et al. [5], and the additional specific heat at each dehydration reaction can be expressed by [4]:

$$
\Delta c=\frac{2.26 \times 10^{6}}{\Delta T}\left(e_{\mathrm{d}} f_{1}+e_{\text {free }}\right) f_{2} \quad\left(\mathrm{~J} / \mathrm{kg} \cdot{ }^{\circ} \mathrm{C}\right),
$$

where $\Delta c$ is the average additional specific heat,

$e_{\mathrm{d}} \quad$ is the dehydration water content (percentage by total weight),

$e_{\text {free }}$ is the free water content (percentage by total weight),

$\Delta T$ is the temperature interval,

$f_{1}, f_{2}$ are correction factors to account for the heat of reactions and effects of water movement.

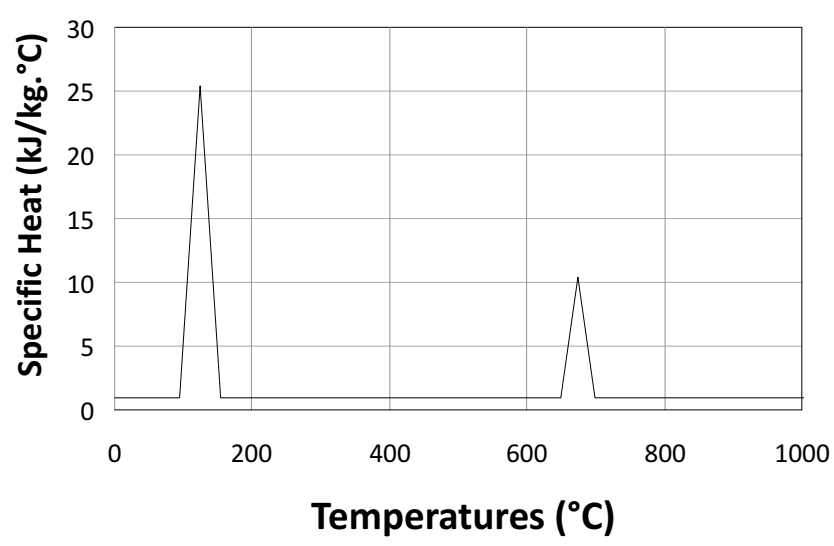

Fig. 3: Specific heat of gypsum as used in the analysis

According to Ang and Wang [4], $f_{1}=1.28$ and 1.42 for the first and second dehydration reactions, respectively. For standard fire conditions $f_{2}=1.4$.

Due to evaporation of water, the density of gypsum reduces with temperature increase. Fig. 4 shows the density

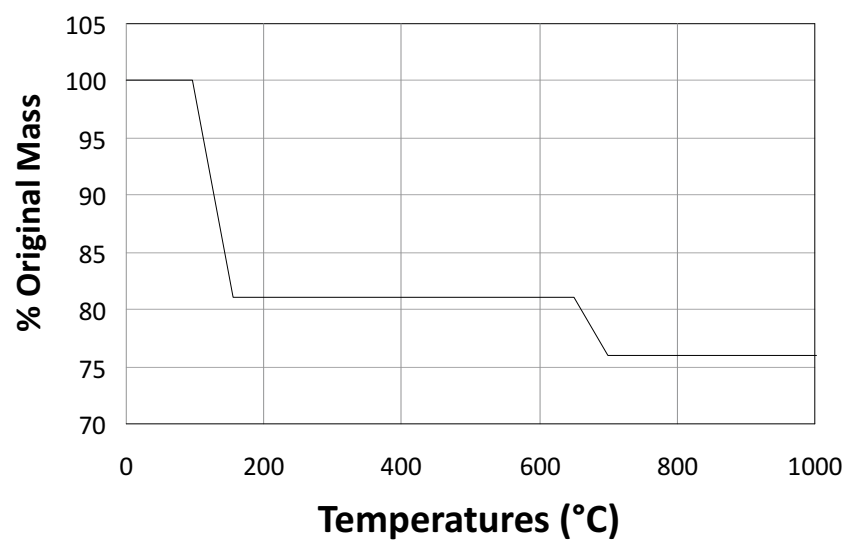

Fig. 4: Density of gypsum as used in the analysis (\% of the original density) 
used in the modelling as a percentage of the original density of gypsum at ambient temperature.

\subsection{Thermal conductivity}

Since gypsum is a porous material, heat transfer through gypsum is a combination of all three modes: conduction through the solid, and convection and radiation through the pores. Therefore the effective thermal conductivity of gypsum should include these effects. This effective thermal conductivity can be affected by many factors such as temperature, density, moisture content and porosity of the material. Such sensitivity contributes to the diverse data reported in literature as demonstrated in Fig. 5. Assuming gypsum is made of solid substrate and uniformly distributed spherical pores, the effective thermal conductivity of gypsum may be calculated using the following equation [6]:

$$
k^{*}=k_{\mathrm{S}} \frac{k_{\mathrm{g}} \varepsilon^{\frac{2}{3}}+\left(1-\varepsilon^{\frac{2}{3}}\right) k_{\mathrm{S}}}{k_{\mathrm{g}}\left(\varepsilon^{\frac{2}{3}}-\varepsilon\right)+\left(1-\varepsilon^{\frac{2}{3}}+\varepsilon\right) k_{\mathrm{S}}},
$$

where $k^{*} \quad$ is the effective thermal conductivity of gypsum,

$k_{\mathrm{g}} \quad$ is the effective thermal conductivity of gas to account for heat transfer in the pores,

$k_{\mathrm{S}} \quad$ is the thermal conductivity of the solid,

$\varepsilon \quad$ is the porosity of the material (the ratio of the volume of void to the overall volume).

In this study, the thermal conductivity of solid dried gypsum $\left(k_{\mathrm{S}}\right)$ is $0.31 \mathrm{~W} / \mathrm{m} \cdot{ }^{\circ} \mathrm{C}$ and the porosity of gypsum is $67 \%-72 \%$.

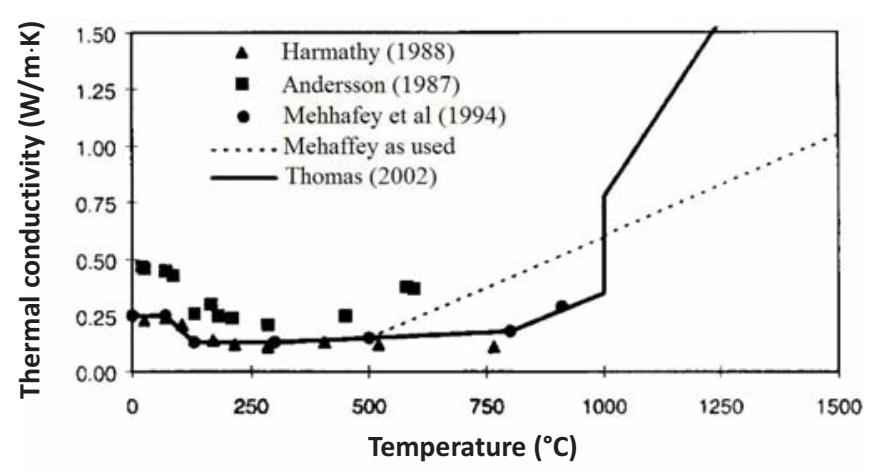

Fig. 5: Thermal conductivity of gypsum, as reported by various researchers [7]

Since the size of the pores is very small (never larger than $5 \mathrm{~mm}$ ), natural convection in the pores can be neglected. Therefore the effective thermal conductivity of the gas is [6]:

$$
k_{\mathrm{g}}=4.815 \times 10^{-4} T^{0.717}+\frac{2}{3} \times 4 d_{\mathrm{e}} \sigma T^{3}
$$

where $T$ is absolute temperature and $d_{\mathrm{e}}$ is the effective diameter of the pores. In this study $d_{\mathrm{e}}=0.15 \mathrm{~mm}$.

Hence, the effective thermal conductivity-temperature relationship consists of three parts, as demonstrated in Fig. 6:

1) Constant thermal conductivity up to $95^{\circ} \mathrm{C}$ before water evaporation, equal to that at ambient temperature, reported by the manufacturer;

2) Linear reduction of conductivity to $0.1 \mathrm{~W} / \mathrm{m} \cdot{ }^{\circ} \mathrm{C}$ at $155^{\circ} \mathrm{C}$;
3) Non-linear increase in thermal conductivity based on equations 9 and 10 .

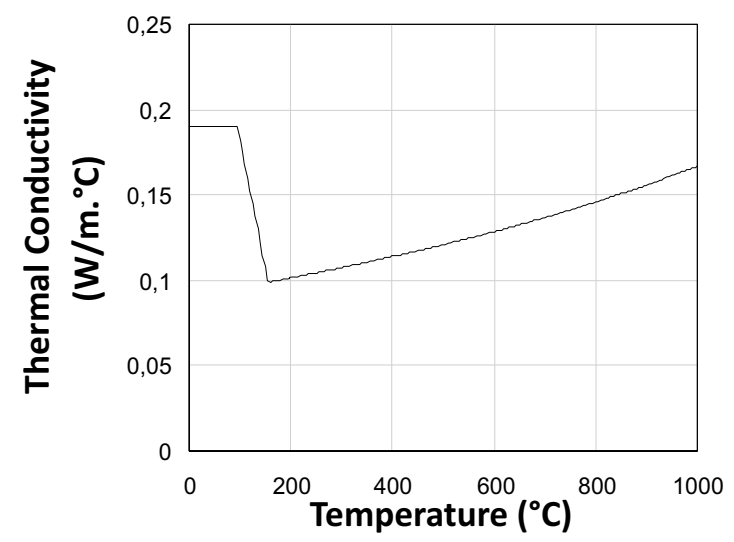

Fig. 6: Effective thermal conductivity of gypsum as used in this study

\section{Small-scale high temperature tests}

A limited number of small-scale experiments have been performed. The specimens tested were gypsum board panels of two different types; $12.5 \mathrm{~mm}$ Gyproc Fireline plasterboard and $9.5 \mathrm{~mm}$ Gyproc Wallboard plasterboard, both British Gypsum products. A total number of 8 specimens were tested, as specified in Table 1. All specimens had approximate dimensions of mm. Each specimen was placed horizontally on top of an electric kiln, as the source of heat, so that one side of the panel was subjected to kiln temperature and the other side faced up to the room temperature $\left(19-25^{\circ} \mathrm{C}\right)$. An opening of $280 \times 265 \mathrm{~mm}$ on the top lid of the kiln allowed the lower side of the panel to be exposed to the elevated kiln temperatures. A $30 \mathrm{~mm}$ layer of glass wool (with an opening of the same size as that in the kiln lid) was laid underneath the specimen to insulate the contact surface between the top lid and the plasterboard. Fig. 7 shows the typical set-up of the experiments. Fig. 8 shows the heating curve achieved in the kiln, which is compared to a standard cellulosic fire (BS476) [8]. Temperatures were measured on the unexposed side, the midpoint (for double layered panels) and the exposed side of the gypsum panel using Type K thermocouples.

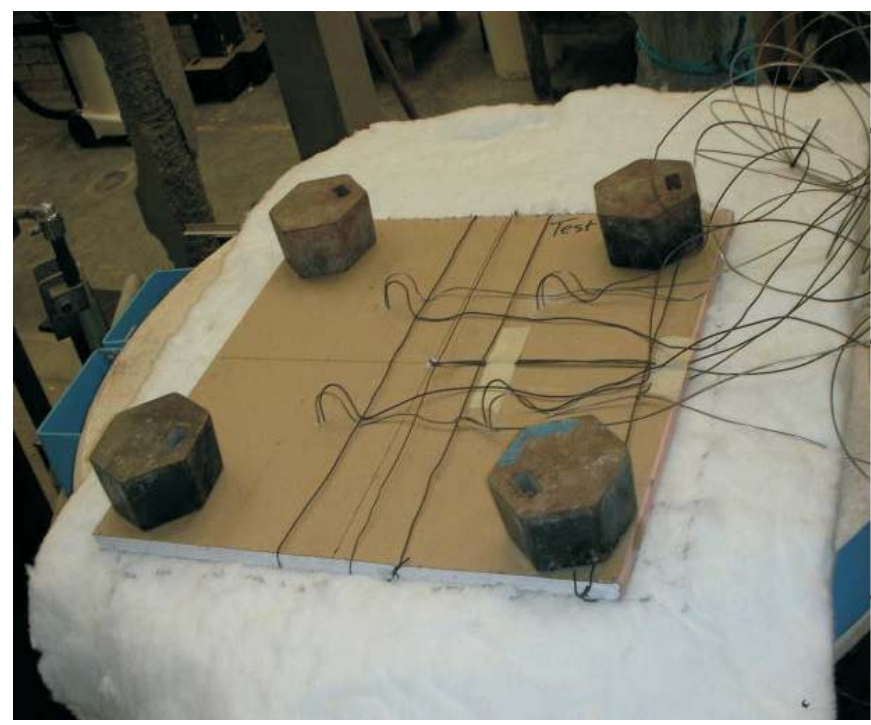

Fig. 7: Typical set-up for the small-scale fire tests 
Table 1: Specifications of gypsum board specimens

\begin{tabular}{|c|l|l|c|c|c|c|}
\hline $\begin{array}{c}\text { Test } \\
\text { No }\end{array}$ & \multicolumn{1}{|c|}{$\begin{array}{c}\text { Plaster board } \\
\text { Type }\end{array}$} & Layers & $\begin{array}{c}\text { Total Thickness } \\
(\mathrm{mm})\end{array}$ & $\begin{array}{c}\text { Density } \\
\left(\mathrm{kg} / \mathrm{m}^{3}\right)\end{array}$ & $\begin{array}{c}\text { Free Water } \\
(\% \text { by weight })\end{array}$ & $\begin{array}{c}\text { Initial Thermal } \\
\text { Conductivity }\left(\mathrm{W} / \mathrm{m} \cdot{ }^{\circ} \mathrm{C}\right)\end{array}$ \\
\hline 1 & Gyproc Fireline & Single & 12.5 & 770 & 3.5 & 0.24 \\
\hline 2 & Gyproc Fireline & Single & 12.5 & 770 & 3.5 & 0.24 \\
\hline 3 & Gyproc Fireline & Double & 25 & 770 & 3.5 & 0.24 \\
\hline 4 & Gyproc Fireline & Double & 25 & 770 & 3.5 & 0.24 \\
\hline 5 & Gyproc Wallboard & Single & 9.5 & 641 & 3.5 & 0.19 \\
\hline 6 & Gyproc Wallboard & Single & 9.5 & 641 & 3.5 & 0.19 \\
\hline 7 & Gyproc Wallboard & Double & 19 & 641 & 3.5 & 0.19 \\
\hline 8 & Gyproc Wallboard & Double & 19 & 641 & 3.5 & 0.19 \\
\hline
\end{tabular}

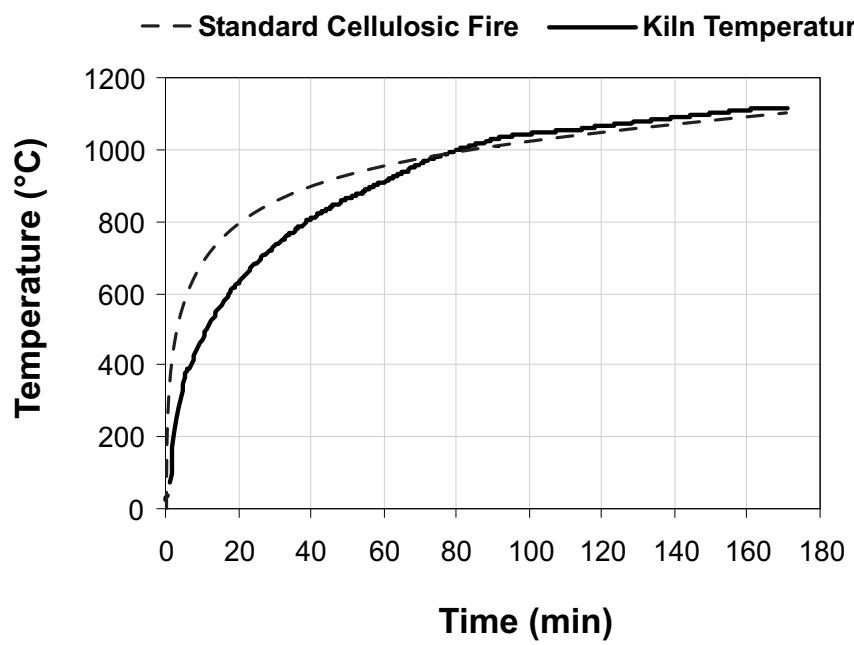

Fig. 8: Time-temperature curve for the kiln against standard cellulosic fire curve

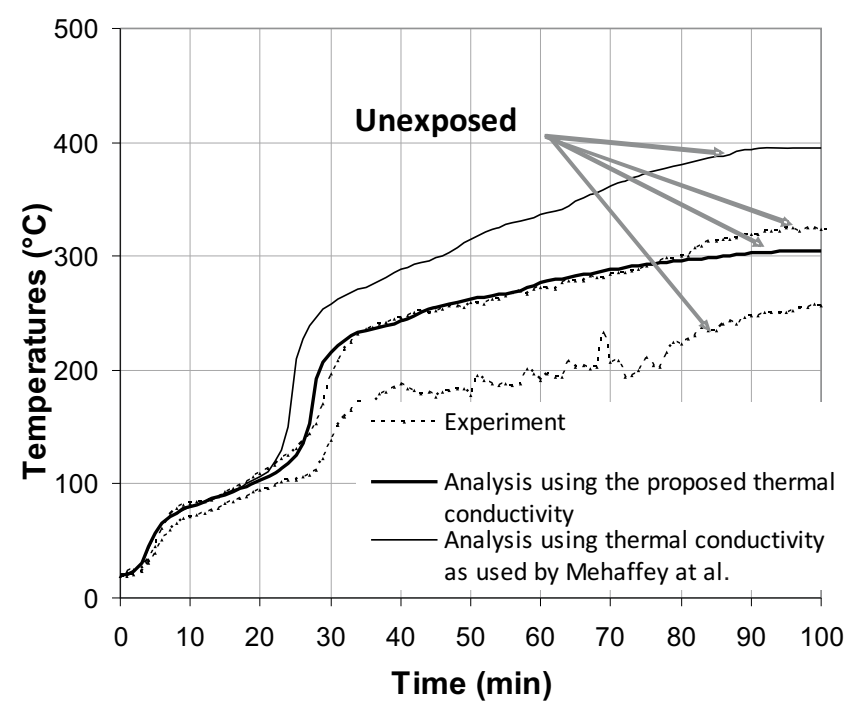

Fig. 9: Temperature history for $12.5 \mathrm{~mm}$ Fireline gypsum panel

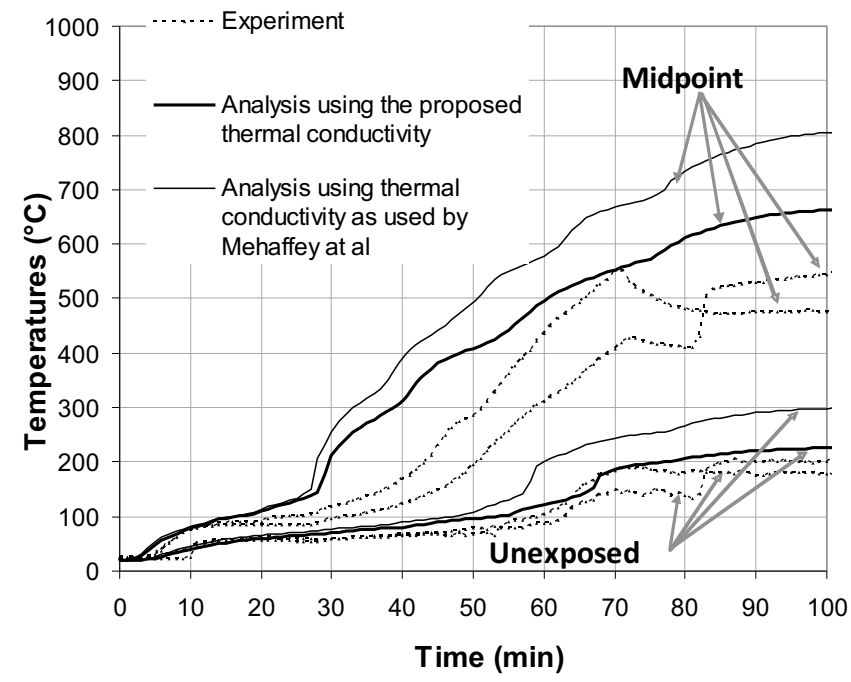

Fig. 10: Temperature history for $25 \mathrm{~mm}$ Fireline gypsum panel

\section{Results}

In Figs. 9 to 12, the temperature histories measured from the tests (data points) and calculated by the program using

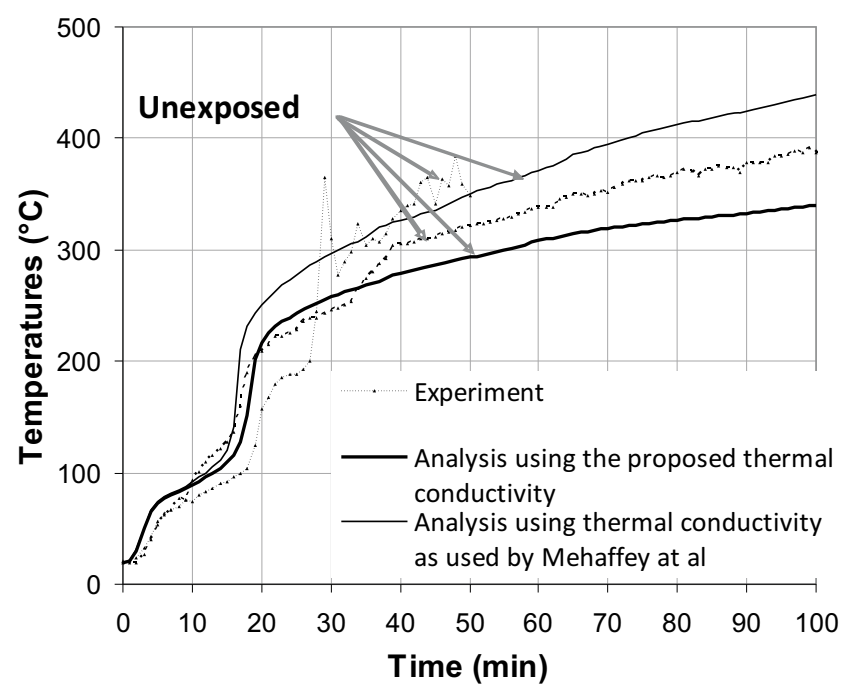

Fig. 11: Temperature history for $9.5 \mathrm{~mm}$ Wallboard gypsum panel 


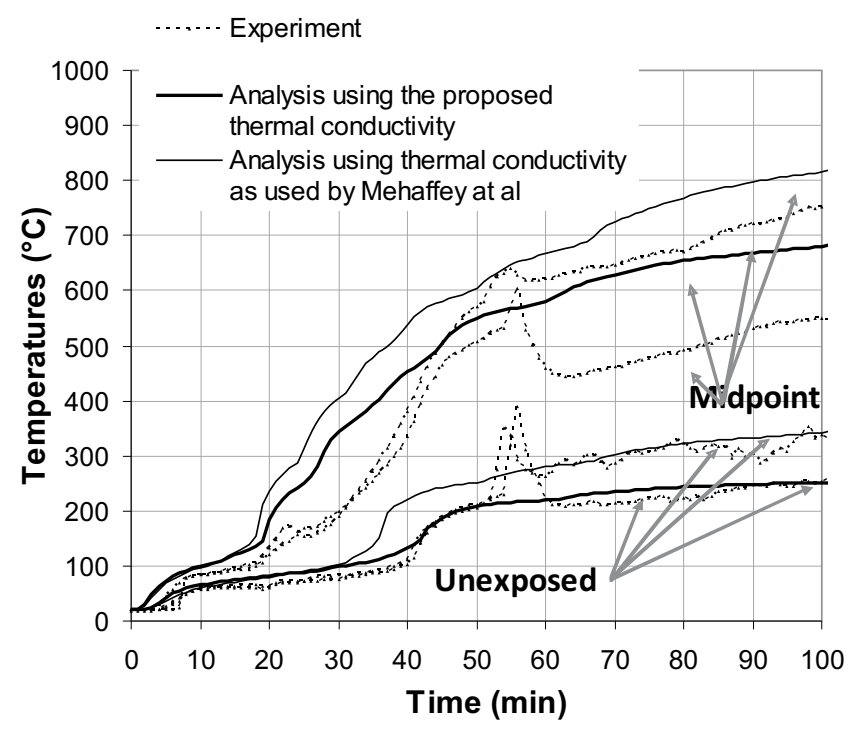

Fig. 12: Temperature history for $19 \mathrm{~mm}$ Wallboard gypsum panel

pore size of $1 \mathrm{~mm}$ (solid thick line) are compared. Also plotted in these figures are the numerical results utilizing thermal conductivity of gypsum, as used by Mehaffey et al. [5] (thin solid line). The results demonstrate a considerable improvement in prediction of temperature development through gypsum when using the new thermal conductivity model described in this paper.

\section{Conclusions}

This paper has presented a hybrid method to determine the effective thermal conductivity of gypsum at high temperatures, based on using small-scale experimental results and a thermal conductivity model which includes the effects of radiation in voids. Despite the simplicity of the method, the results are in good agreement with test measurements and show great improvement when compared to those produced using thermal conductivity values reported in literature. This method will aid manufacturers to develop their products without having to conduct numerous large-scale fire tests. Further planned research includes investigating the effects of discrete large cracks in gypsum on heat transfer in gypsum board systems and gypsum falling-off at high temperatures.

\section{Acknowledgment}

The authors would like to thank British Gypsum for their financial support and Drs. Kane Ironside and Jan Rideout for their interest and technical support. The technical assistance by the laboratory staff at the University of Manchester is greatly appreciated.

\section{References}

[1] Rahmanian, I.: Fire Resistance of Gypsum Board Based Systems. First year PhD progression report, School of Mechanical, Aerospace and Civil Engineering, University of Manchester, UK, 2008.

[2] Wang, H. B.: Heat Transfer Analysis of Components of Construction Exposed to Fire. Department of Civil Engineering and Construction, University of Salford, U.K., 1995.

[3] Ozisik, M. N.: Heat Transfer: A Basic Approach. New York; London: McGraw-Hill, 1985.

[4] Ang, C. N., Wang, Y. C.: The Effect of Water Movement on Specific Heat of Gypsum Plasterboard in Heat Transfer Analysis Under Natural Fire Exposure. Construction and Building Materials, Vol. 18 (2004), p. 505-515.

[5] Mehaffey, J. R., Cuerrier, P., Carisse, G. A.: A Model for Predicting Heat Transfer Through Gypsum-Board/Wood-Stud Walls Exposed to Fire. Fire and Materials, Vol. 18(1994), p. 297-305.

[6] Yuan, J.: Fire Protection Performance of Intumescent Coating under Realistic Fire Conditions. PhD Thesis, School of Mechanical, Aerospace and Civil Engineering, University of Manchester, UK, 2009.

[7] Thomas, G.: Thermal Properties of Gypsum Plasterboard at High Temperatures. Fire and Materials, Vol. 26 (2002), p. 37-45.

[8] BS476, Fire tests on building materials and structures, Part 20: Method for determination of the fire resistance of elements of construction (general principles), British Standards Institution, 1987.

Ima Rahmanian

e- mail: ima.rahmanian@postgrad.manchester.ac.uk

Yong Wang

University of Manchester

School of Mechanical, Aerospace and Civil Engineering,

Manchester, PO Box 88

Manchester M60 1QD, United Kingdom 